\title{
Battling Soil-Transmitted Intestinal Worm Disease: From the Hookworm Campaigns of the Rockefeller Foundation to Contemporary Mass Drug Administration
}

James L. A. Webb, Jr.

\section{Summary}

In the early twentieth century, the Rockefeller Sanitary Commission and the Rockefeller Foundation's International Health Board (later, International Health Division) undertook campaigns in a number of world regions to treat hookworm disease and to promote 'sanitation,' that is, improved excreta disposal. The campaigners learned that chemical therapy would not clear all hookworm infections, and they were unable to mobilize the support of governments for the reform of open defecation practices. Some campaigns achieved successes in reducing disease, but they were discontinued in the 1920s on the understanding that sanitation programs were foundational for success in eliminating hookworm disease. In the first decade of the twentyfirst century, under the rubric of "Neglected Tropical Diseases," global health organizations re-engaged the struggle against all three soil-transmitted helminth (STHs) infections - hookworm, roundworm, and whipworm. The new campaigners rolled out mass drug administration (MDA) programs to reduce the incidence of disease without programs to improve excreta disposal. This approach effectively ignored the lessons of the early twentieth century campaigns. Intestinal worm transmission continued, and the efficacy of the MDA programs was threatened by the emergence of helminthic drug resistance.

Keywords: hookworm, roundworm, whipworm, soil-transmitted helminths, Rockefeller Sanitary Commission, Neglected Tropical Diseases, sanitation

James L. A. Webb, Jr., Department of History, Colby College, 5328 Mayflower Hill Drive, Waterville, Maine 04901 USA (jlwebb@colby.edu) 
Soil-transmitted intestinal worms - hookworm, roundworm, and whipworm - are among the most common human infections. By a 2010 estimate, the number of people infected by hookworm was in the range of 576-740 million, roundworm approximately 1 billion, and whipworm about threequarters of a billion. ${ }^{1}$ All three worm infections are transmitted by eggs that are passed in the feces of infected individuals. Hookworm larvae develop in the polluted soil and attach themselves to human feet or hands through dermal contact. Roundworm and whipworm eggs are ingested via an oralfecal route. All three worms make their ways to the human intestines. Hookworms and whipworms attach themselves to the intestinal walls and draw blood. Roundworms live from other nutrients in the intestines. The universal disposal of feces in latrines or by other sanitary means fully breaks the cycle of transmission.

The health consequences of intestinal worm infections range from the symptomless to the life threatening. Moderate and heavy infections are implicated in insidious health effects such as anemia, nutritional stress, and impaired physical and mental development. ${ }^{2}$ Light infections may convey health benefits, including a lower risk of allergic and autoimmune diseases. The diagnosis of intestinal worm disease is complicated by the fact that many individuals are infected with more than one intestinal worm species and/or with other parasitic diseases such as malaria that produce similar symptoms such as anemia.

\section{Hookworm Emerges as an Important Global Infection}

In 1843, the Milanese physician Angelo Dubini discovered and described hookworm as a human intestinal parasite; in 1853, the German physician Wilhelm Greisinger and his protégé Theodor Bilharz implicated hookworm in widespread anemia in Egypt; and in the mid 1860s, Otto Wucherer, a Portuguese physician who had immigrated to Brazil, confirmed the findings of Greisinger and Bilharz that associated hookworm infection with anemia. In the late nineteenth century, an epidemic of severe hookworm infections among workers digging the St. Gotthard tunnel in Switzerland brought the issue of hookworm disease to the fore. Physicians discovered heavy infec-

1 Brooker 2010.

2 Crompton/Nesheim 2002, 52-53. The parasite-stress hypothesis holds that in newborns, the brain demands 87 percent of the metabolic budget, decreasing to 44 percent at age 5, 34 percent at age 10, and 23 and 27 percent for adult males and females, respectively. See Eppig, Fincher, Thornhill 2012. 
tions of hookworm in post-mortem examinations, and these discoveries led to the treatment of those suffering or at risk from what had previously been known as 'miner's disease'. In Germany, Austria, and England, governments created joint programs to reduce or clear the intestinal worm infections by treating with oral remedies from the herbal medical cabinet that had proved effective against roundworm and tapeworm. Two recognized anthelminthic therapies - extracts of male fern (Dryopteris filix-mas) and the essential oil of thyme (Thymus vulgaris) known as thymol - eliminated hookworm eggs from the feces of those infected by hookworm.

In the early twentieth century, researchers found that rural populations in the Caribbean and the southern United States were also infected with hookworm. Soon, the U.S. military initiated a hookworm disease control program in Puerto Rico, and in 1904 Costa Rican physicians launched the first national hookworm campaign. Public health officials in Brazil, Colombia, El Salvador, and Guatemala developed more limited programs in parallel with Costa Rica. These public health programs provided chemical therapy for hookworm sufferers and educational messages about the need for latrines to reduce hookworm transmission.

Interest in hookworm control grew. In 1908, the British Colonial Office created a hookworm committee. ${ }^{3}$ In 1909, the state of Florida began a hookworm control program, and the same year, the John D. Rockefeller provided $\$ 1$ million to fund a program in the southern United States to control hookworm disease. ${ }^{4}$

From 1910-1914, the Rockefeller Sanitary Commission (RSC) advanced a program of hookworm treatment and sanitation in the southern United States. The RSC goals were to control hookworm disease, raise public awareness about the infection, and stimulate local and state governments to

3 Palmer 2010, 9-13, 38-39.

4 Although the Rockefeller initiative was called the Rockefeller Sanitary Commission to Eradicate Hookworm Disease, its goal was control hookworm disease. As the DirectorGeneral of the International Health Commission wrote in the first annual report: "The International Health Commission has not undertaken to eradicate uncinariasis (hookworm disease) in any country. The accomplishment of this work will require the operation of permanent agencies working over long periods of time. The attitude assumed by the International Health Commission towards this work is that assumed by the Rockefeller Sanitary Commission in the Southern States, namely, that the bringing of this disease under control in any country is a work which no outside agency, working independently, could do if it would, and one which no outside agency should do if it could; that if the infection is to be stamped out in any area the country in which it exists must assume the responsibility; and that the Commission may be of service in so far as it may co-operate in the relief and control of this disease."

Cited in National Archives of the United Kingdom, Enclosure in No. 26. Grenada, International Health Commission. $1^{\text {st }}$ October 1915. Angus MacDonald, Medical Officer in Charge, pp. 44-45. 
adopt public health programs to prevent transmission. In 1913, John D. Rockefeller founded the Rockefeller Foundation, and the same year its directors created an International Health Commission (1913-1916) later renamed the International Health Board (IHB) - to collaborate with national and colonial governments to extend hookworm control and to spread the gospel of sanitation. In the early decades of the twentieth century, public health authorities considered hookworm to be a major global disease. The IHB participated in collaborative public health campaigns in British Guiana, the Caribbean, Mexico, Brazil, Egypt, India, Ceylon, the Malay States, Java, the Philippines, and beyond, with widely varying results. ${ }^{5}$

\section{Varied Results}

When the RSC campaigns abruptly ended by administrative decision in 1914, they had neither eradicated hookworm disease nor converted the rural populations throughout the southern United States to regular latrine usage. ${ }^{6}$ During the 1930s, epidemiologists conducted surveys of hookworm prevalence in eight of the southern states. Their results indicated highly varied impacts from the RSC campaigns. ${ }^{7}$ In North Carolina, hookworm prevalence had dropped from 36.6 to 12.3 percent. Treatment with thymol during the RSC campaign had reduced the worm burden, but reinfection had beset a large number of those treated. ${ }^{8}$ In South Carolina, prevalence had declined more modestly - from 37.3 to 24.8 percent - and there was still a hookworm problem of major proportions. The average intensity of infection was high enough to produce clinical morbidity. ${ }^{9}$ In Louisiana, a broad public educational effort to convey new understandings of hygiene and sanitation enjoyed success. Over time, a wide array of new practices, including the construction of septic systems on farms, sewer lines in rural towns, better sanitation in the schools, and more people wearing shoes, had a profound impact on the prevalence of hookworm infections. This could not be attributed to hook-

\footnotetext{
5 Male fern became the chemical therapy of choice within Europe, and thymol in the United States and in the overseas IHB programs. During the First World War, thymol was in short supply, and many of the IHB programs experimented with oil of chenopodium and synthetic chemical therapies.

6 Ettling 1981, 177.

7 The results were also only roughly accurate owing to dissimilar sampling methodologies and laboratory techniques used in the early and later surveys.

8 Keller, Leathers, Knox 1937, 440, 450; Link 1990, 10, 17, 22.

9 Leathers, Keller, Wyman 1936, 602-603, 612-614.
} 
worm therapy-only about 5 percent of Louisiana's population was ever treated with a vermifuge. ${ }^{10}$

The largest impact of the RSC programs in the southern United States was to spur the creation of state public health systems that took on the challenge of building sanitary privies and discouraging open defecation. The transformation in sanitation, however, was slow. By the early 1930s, many regions still lacked basic sanitation. During the economic depression of the 1930s, the U.S. government, through the Civil Works Administration and other agencies, built about three million privies across rural America. According to the 1940 census, in the rural U.S., there were about 6.3 million privies serving rural homes. By a conservative estimate, another 4 million were needed. ${ }^{11}$

\section{Treatment, Sanitation, and Reinfection}

Beyond the United States, researchers in follow-up studies examined the relationships between treatment, sanitation, and reinfection. Following treatment without improved sanitation, reinfection occurred, although with considerable variation as to extent and intensity. In Puerto Rico, for example, one year after hookworm treatment, a population without improved sanitation had experienced nearly 100 percent reinfection with an average worm load reduced by about 50 percent, and a population with sanitation had an infection rate of nearly 50 percent with an intensity reduced by 88 percent. ${ }^{12}$ On the island Ilha do Governador in Brazil, IHB researchers led an aggressive program of latrine construction and treatment of the infected. After four years of work, the percentage of those infected had barely declined (from 71.2 percent to about 70 percent). They found, however, that a single standard treatment would reduce the worm burden by 90 to 95 percent, and that two treatments in heavily infected individuals would reduce the worm burden to 25 worms or fewer. They deemed this an economic cure, and in their view it was not medically necessary to do more. ${ }^{13}$ In southern India researchers discovered that they could achieve substantial reductions in the intensity of hookworm infections through sanitation alone or by relocation away from soil pollution. ${ }^{14}$

10 Waisley 2000, 41, 67-68.

11 Tisdale, Atkins 1943, 1319-1322.

12 Hill 1925, 667.

13 Smillie, Augustine 1926, 166.

14 Mhaskar 1920, 398-399. 
Few governments took up the challenge to improve basic sanitation, and the IHB came to the view that it was not possible to jumpstart public health programs overseas by treating hookworm infections and advocating for sanitation. The IHB determined not carry out further hookworm campaigns unless the sanitary infrastructure was already in place and in use. This meant that the hookworm campaigns effectively ended by the mid 1920s. ${ }^{15}$

\section{World Health Organization Initiatives}

Beginning in the mid 1950s, the World Health Organization convened expert committees on soil-transmitted helminthic infections and launched surveys to stimulate programs of treatment and human waste management. These programs, however, made little headway against open defecation and STHs in the tropics. By the 1970s, an emphasis on viral and bacterial intestinal diseases that cause considerable mortality virtually eclipsed the focus on helminthic infections. It was not until 1980 that the WHO re-engaged with the large health impacts of STHs and restarted a program of research and control of gastrointestinal helminthic infections. ${ }^{16}$

Although STH infections were among the most ubiquitous human infections, public health policy-makers found it difficult to mobilize resources for their control. ${ }^{17}$ Relatively small percentages of those infected suffered developmental consequences, and even smaller percentages suffered clinically severe symptoms ${ }^{18}$ STHs had difficulty competing against other infectious diseases for attention.

An approach - like that of the IHB in an earlier era - that stressed the primacy of sanitation seemed infeasible. In sub-Saharan Africa, South Asia, and Southeast Asia, open defecation practices proved very difficult to change. Public health specialists recognized improved sanitation as essential but unachievable goal, at least in the short and medium term. If sanitation could not be a pillar of STH intervention, because of the difficulty and expense of individual screenings for STHs, the only intervention option seemed to be mass treatment.

15 Farley 2004, 70-71.

16 Bundy, Cooper 1989, 108.

17 This was in part because of the difficulties in quantifying the economic and health costs of the infections. Guyatt, Evans 1992, 397-402.

18 The percentages of those infected by hookworm, whipworm, and roundworm and suffering from developmental consequences were estimated at $2.38 \%, 3.22 \%$, and $5.19 \%$ respectively. Chan et al. 1994, 380-382. 
In the 1990s, a 'new drug strategy' that was known as preventive chemotherapy for STH control gained traction. It was based on the idea of using a population-wide approach using the anti-parasitic drugs albendazole and mebendazole that would target helminthic infections broadly, rather than the older approach that targeted individuals with disease symptoms.

In the Americas and in Asia, from the 1990s until the early 2000s, some governments launched helminth control programs using anti-parasitic drug therapy, and some governments and non-governmental organizations (NGOs) had success in improving access to potable water and safer excreta disposal systems. These advances took place in a broader context of ongoing economic development and urbanization and reduced the morbidity and mortality from STHs. It was not possible to sort out their relative importance. The contrast with sub-Saharan Africa was stark. There appeared to have been no change in sub-Saharan African prevalence rates, and due to rapid population growth, the absolute numbers of infections dramatically increased. ${ }^{19}$

\section{Ignoring the Lessons of the Past}

In 2005, public health advocates for aggressive intervention to control STHs and other tropical diseases grouped them under the new rubric 'Neglected Tropical Diseases' (NTDs). ${ }^{20}$ They secured commitments from pharmaceutical companies to donate large quantities of the anthelminthic drugs albendazole and mebendazole at extremely low cost. This made it possible to treat large numbers of those infected and fueled an enthusiasm for mass drug administration. In 2012, schoolchildren took some 260 million tablets of albendazole and mebendazole, and a total of 700 million persons received treatment for STHs. ${ }^{21}$

The NTD programs were designed without reference to the historical experiences of the RSC and IHB. They eschewed the goal of improved sanitation, implicitly conceding that reinfection with the STHs would be ongoing and that it would be necessary to provide deworming medicines on a routine basis. This open-ended commitment to control was vulnerable to criticism because without large-scale epidemiological surveys it was not possible to

19 de Silva et al. 2003,548 .

20 Savioli 2011, 483-486.

21 Savioli 2014, 665-666. The treatment programs have reduced the risks of infection from STHs in South America and Asia, although progress has remained slow in sub-Saharan Africa, the region with the highest prevalence. Karagiannis-Voules, et al. 2015, 74. 
measure the impact of the interventions, and medical anthropologists demonstrated that the implementation of a single approach to parasitic worm control had different outcomes in different political, economic, historical and social contexts. ${ }^{22}$

In order to bolster support for the deworming initiative, its promoters had cited evidence that the mass administration of deworming drugs would improve school attendance and performance. One putative strand of support was based upon a curious interpretation of the goals and outcomes of the RSC in the southern United States that held that the RSC had set out to eradicate hookworm, had done so, and that this had resulted in improved educational outcomes and economic growth. ${ }^{23}$ Other scholars advanced statistical evidence concerning the results of deworming on school performance in Kenya, ${ }^{24}$ but the study was later debunked by an article in the British Medical Journal. ${ }^{25}$ In 2015, a Cochrane Database systematic survey of the literature discovered no evidence for the positive impact of deworming on school attendance and performance. ${ }^{26}$

Experts soon began to call for more attention to integrating improved sanitation into the STH control programs. To many, it was clear that the mass drug administration programs could not fully address the problem of STH infections, and that hybrid programs that integrated sanitation would produce far better outcomes. ${ }^{27}$ This was, of course, a return to the principal learning from the long record of the RSC and IHB interventions: improved excreta disposal was basic to any effort to eliminate the burden of intestinal worm disease.

\section{The Long Sweep of Helminthic Disease Control}

There are important differences between the contemporary STH control programs and those of the RSC and IHB a century earlier. The drugs albendazole and mebendazole are safer and less expensive than the first-generation anthelminthics thymol and oil of chenopodium. The contemporary programs are far larger in scope. The administration of anthelminthic drugs to many schoolchildren in the tropics is routine. This has resulted in a

22 Palmer, Allen 2011.

23 Bleakley 2007.

24 Miguel, Kremer 2004.

25 Hawkes 2012; Aiken, et al. 2015.

26 Taylor-Robinson, et al. 2015.

27 Ziegelbauer, et al. 2012; Strunz, et al. 2014. 
substantial decrease in morbidity and mortality. It has also produced drug resistance in the helminths. ${ }^{28}$

Today, scientific understandings of the health consequences of light helminthic infections are substantially different from those of a century ago. Contemporary research suggests that light infections may improve some aspects of the immune response to hyper-inflammatory diseases. Murine models support the hypothesis that light helminthic infections might be therapeutic - that is, that the helminths or their biochemical products might be beneficial for conditions such as inflammatory bowel disease and multiple sclerosis. Some researchers view the large scale deworming of tropical populations as an opportunity to investigate prospectively the impact of vermifuges on the prevalence of allergic or other inflammatory diseases. This suggested the possibility that the deworming programs might lead to the emergence of inflammatory or metabolic conditions that could assume epidemic proportions in countries with weak health systems that are unprepared for this challenge, and experts called for studies to assess this risk. ${ }^{29}$

The contemporary campaign by global health organizations to control STHs has relied upon inexpensive drugs and a top-down design to reduce the burden of disease. It has had some successes, but its effectiveness has been compromised by a failure to learn from the historical epidemiological record of the earlier RSC and IHB campaigns. ${ }^{30}$ Contemporary global disease control programs such as that to control STHs incur an unnecessary public health risk when they ignore the lessons of past programs. ${ }^{31}$

\section{Bibliography}

Aiken, Alexander M./Calum Davey Calum, /James R Hargreaves/Richard J Hayes, "Re-analysis of Health and Educational Impacts of a School-based Deworming Programme in Western Kenya: A Pure Replication", International Journal of Epidemiology 44, Issue 5, 1 October (2015), 1572-1580

Bleakley, Hoyt, "Disease and Development: Evidence from Hookworm Eradication in the American South," Quarterly Journal of Economics, 122 (2007) 73-117

Brooker, Simon, "Estimating the Global Distribution and Disease Burden of Intestinal Nematode Infections: Adding Up the Numbers - A Review", International Journal of Parasitology 40 (2010) 1137-1144

28 This repeats the experience of veterinarians who for decades have used the same class of drugs to deworm livestock and produced widespread drug resistance to the animal helminths. Choffnes, Relman 2011, 69.

29 Wammes, et al. 2014, 1159.

30 For other examples of top-down programs, see Giles-Vernick, Webb 2013.

31 For a broader discussion of the relationship of historical epidemiology to global health, see Webb 2015. 
Bundy, D.A.P./E.S. Cooper, "Trichuris and Trichuriasis in Humans", Advances in Parasitology 28 (1989) 107-173

Chan, M.S./G.F. Medley/D. Jamison/D.A. Bundy, "The Evaluation of Potential Global Morbidity Attributable to Intestinal Nematode Infections", Parasitology 109 (1994) 373-387

Choffnes, Eileen R./David A. Relman (rapporteurs), The Causes and Impacts of Neglected Tropical and Zoonotic Diseases: Opportunities for Integrated Intervention Strategies: Workshop Summary (Washington 2011)

Crompton, D.W.T./M.C. Nesheim, "Nutritional Impact of Intestinal Helminthiasis During the Human Life Cycle", Annual Review of Nutrition 22 (2002) $35-59$

de Silva, Nilanthi R./Simon Brooker/Peter J. Hotez/Antonio Montresor/Dirk Engels/ Lorenzo Savioli, "Soil-Transmitted Helminth Infections: Updating the Global Picture", Trends in Parasitology 19 (2003) 547-551

Eppig, Christopher/Corey L. Fincher/Randy Thornhill, "Parasite Prevalence and the Worldwide Distribution of Cognitive Ability", Proceedings of the Royal Society: Biological Sciences 277 (2010) 3801-3808

Ettling, John, The Germ of Laziness: Rockefeller Philanthropy and Public Health in the New South (Cambridge, MA 1981)

Farley, John, To Cast Out Disease: A History of the International Health Division of the Rockefeller Foundation (1913-1951) (New York 2004)

Giles-Vernick, Tamara/James L.A. Webb, Jr. (eds.), Global Health in Africa: Historical Perspectives on Disease Control (Athens, OH 2013)

Grove, David I., A History of Human Helminthology (Wallingford 1990)

Guyatt, H.L./D. Evans, "Economic Conditions for Helminth Control”, Parasitology Today 8 (1922) 397-402

Hawkes, N., 2013. "Deworming Debunked”, British Medical Journal 346 (2013), e8558.

Hill, Rolla B., "Hookworm Reinfestation in Sanitated and Unsanitated Areas", Southern Medical Journal 18 (1925) 665-668

Karagiannis-Voules, Dimitrios-Alexios/Patricia Biedermann/Uwem F. Ekpo/ Amadou Garba/Erika Langer/Els Mathieu/Nicholas Midzi/et al., "Spatial and Temporal Distribution of Soil-Transmitted Helminth Infection in Sub-Saharan Africa: A Systematic Review and Geostatistical Meta-Analysis", Lancet Infectious Diseases 15 (2015) 74-84

Keller, A.E./W.S. Leathers/J. C. Knox, "The Present Status of Hookworm Infestation in North Carolina", American Journal of Hygiene 26 (1937) 437-454

Leathers, W. S./A.E. Keller/B.F. Wyman, "A State-Wide Investigation of Hookworm in South Carolina", American Journal of Epidemiology 23 (1936) 600-614

Link, William A., “'The Harvest is Ripe, But the Laborers Are Few': The Hookworm Crusade in North Carolina, 1909-1915", North Carolina Historical Review 67 (1990) 1-27

Miguel, E./M. Kremer, "Worms: Identifying Impacts On Education and Health In The Presence Of Treatment Externalities", Econometrica 72 (2004) 159-172

Mitchell, Piers D., "The Origins of Human Parasites: Exploring the Evidence for Endoparasitism Throughout Human Evolution", in International Journal of Paleopathology 3 (2013) 191-198 
Mhaskar, K. S., "Hookworm and Sanitation", Indian Journal of Medical Research 8 (1920) 398-406

Palmer, Steven, "Migrant Clinics and Hookworm Science: Peripheral Origins of International Health, 1840-1920", Bulletin of the History of Medicine 83 (2009) 676-709

Palmer, Steven, Launching Global Health: The Caribbean Odyssey of the Rockefeller Foundation (Ann Arbor 2010)

Parker, Melissa and Tim Allen, "Does Mass Drug Administration for the Integrated Treatment of Neglected Tropical Diseases Really Work? Assessing Evidence for the Control of Schistosomiasis and Soil-transmitted Helminths in Uganda," Health Research Policy and Systems 9 (2011) 1-20

Savioli, Lorenzo, "Neglected Tropical Diseases: The Development of a Brand with No Copyright. A Shift from a Disease-Centered to a Tool-Centered Strategic Approach", in: Eileen R. Choffnes/David A. Relman (rapporteurs), The Causes and Impacts of Neglected Tropical and Zoonotic Diseases: Opportunities for Integrated Intervention Strategies: Workshop Summary (Washington 2011) 483486

Savioli, Lorenzo, "Preventive Anthelminthic Chemotherapy: Expanding the Armamentarium", New England Journal of Medicine 370 (2014) 665-666

Smillie, W.G./D.L. Augustine, "Hookworm Infestation. The Effect of Varying Intensities on the Physical Condition of School Children", American Journal of Diseases of Children 31 (1926) 151-168

Stiles, Ch. W., Report of the Scientific Secretary (New York 1914)

Stiles, Ch. W., "Decrease of Hookworm Disease in the United States", Public Health Reports 45 (1930) 1763-1791

Strunz, E. C./D. G. Addiss/M.E. Stocks/S. Ogden, J. Utzinger/Matthew C. Freeman, "Water, Sanitation, Hygiene, and Soil-Transmitted Helminth Infection: A Systematic Review and Meta-Analysis", PLoS Medicine 11 (2014) e1001620

Taylor-Robinson, David C., Nicola Maayan, Karla Soares-Weiser, Sarah Donegan, and Paul Garner, "Deworming Drugs for Soil-Transmitted Intestinal Worms in Children: Effects on Nutritional Indicators, Haemoglobin and School Performance," Cochrane Database Systematic Reviews 11 (2015) 1-157

Tisdale, E.S./C.H. Atkins, "The Sanitary Privy and Its Relation to Public Health", American Journal of Public Health 33 (1943) 1319-1322

Utzinger, Jürg, "A Research and Development Agenda for the Control and Elimination of Human Helminthiases", PLoS Neglected Tropical Diseases 6 (2012) e1646

Waisley, Thomas, "Public Health Programs in Early Twentieth-Century Louisiana", Louisiana History: The Journal of the Louisiana Historical Association 41 (2000) 41-69

Wammes, Linda J./Harriet Mpairwe/Alison M. Elliott/Maria Yazdanbakhsh, "Helminth Therapy or Elimination: Epidemiological, Immunological, and Clinical Considerations", Lancet Infectious Diseases 14 (2014) 1150-1162

Webb, Jr., James L.A., "The Historical Epidemiology of Global Disease Challenges", Lancet 323 (2015) 322-323

Ziegelbauer, Kathrin/Benjamin Speich/Daniel Mäusezahl/Robert Bos/Jennifer Keiser/Jürg Utzinger, "Effect of Sanitation on Soil-transmitted Helminth Infection: Systematic Review and Meta-analysis", PLoS Medicine 9 (2012) e1001162 